\title{
Humanidades digitais: $O$ Brasil conectado e as perspectivas de interpretação dos museus em Porto Alegre.
}

\author{
Júlio Bittencourt Francisco bittencourt.francisco@ufrgs.br
}

Resumo: Uma sociedade conectada utiliza um novo conceito de patrimônio que aparece quando o espaço se modifica de físico para o de fluxo de dados em rede. O ciberespaço e as tecnologias possibilitam, além de informações atualizadas para o visitante ou pesquisador permitindo que ele atue como coautor criando, compartilhando e divulgando informações online do acervo do museu, através de uma tela ou dispositivo eletrônico. Este é um fenômeno global que leva os indivíduos a interagir, trocar saberes e absorver mudanças sociais. O texto analisa a sociedade conectada no Brasil e usa o exemplo de Porto Alegre e de seus museus, para caracterizar a participação dessas instituições nas redes sociais.

Palavras chave: Museus; Sociedade digital; Novas tecnologias; Brasil conectado; Museus de Porto Alegre

\section{Digital Humanities: Connected Brazil and the Perspective of Interpreting Museums in Porto Alegre.}

Abstract: A connected society implies a new concept of patrimony which appears when space changes from physical to the one of data flow. Cyberspace and new technologies within the cultural institutions up-to-date information to the visitors or researchers that has the potential to act as a co-author by creating, sharing and disseminating information online from a museum's collection, through the screen or electronic device. This is a global trend and lead individuals to interact, exchange knowledge and absorb social change. The text analyzes the connected society in Brazil and uses the example of the museums of Porto Alegre town in order to characterize its participation in the social media network.

Keywords: Museums; Digital society; New technologies; Connected Brazil; Museums of Porto Alegre 


\section{Introdução}

Atualmente, as novas tecnologias da informação aplicadas em praticamente todas as áreas do conhecimento, assim como o uso da Internet têm colocado em crise conceitos, comportamentos e certezas, mas também modificado práticas e exigido novos conhecimentos por parte dos intelectuais e profissionais. Os museus, de forma significativa, se transformam desde que essas instituições culturais se abriram para novas experiências, e, ao acompanhar uma série de novas tecnologias da informação, categorias, perfis paisagísticos e sociais que os cercam, acrescentaram um público novo. Estas aberturas pressupõe a possibilidade de que experiências individuais e coletivas de comunicação sejam realizadas, sem perder de vista que existe uma dimensão educativa intrínseca dessas instituições. Santos (2008) propõe que a prática museológica tenha como produto a construção do conhecimento, que seja, portanto, educativa. Quando se mostra uma experiência, uma estética ou uma coleção, aprendemos guardando uma emoção, ou seja, quando um museu expõe seus acervos de forma criativa, mostrando através de interfaces interessantes e inovadoras, aumenta seu valor junto ao público e cumpre sua missão.

A novidade desse trabalho é o relato da participação dos brasileiros nas redes sociais e a criação do que chamamos de cartografias museográficas nas redes sociais. Este mapeamento detalha a participação nas redes sociais dos museus e centro culturais da $1^{\mathrm{a}}$ Região Museal do Estado do Rio Grande do Sul, o que corresponde a região metropolitana de Porto Alegre e municípios vizinhos. Neste cenário é importante entender que novos desafios e dilemas sejam impostos aos profissionais de museus, educadores e curadores, mas também ao grande público que, em relação à ampliação dos processos de comunicação digital, e em razão de uma diversidade de alternativas de expografia de comunicação, de pesquisa, de documentação e compartilhamento, se beneficia com o resultado dessas distintas práticas materializadas, que são colocadas disponíveis para todos através da web. Tal realidade permite identificar empiricamente estratégias de divulgação das coleções e de outras informações relativas à instituição, podendo ser acessadas pelo público e atualizadas pelas instituições através da Internet. Além disso, a possibilidade de interação se amplia pelo fato de que as plataformas digitais passam a ser utilizadas de forma ostensiva pelas instituições, alterando significativamente as experiências do público, mas também criando uma dinâmica nova no âmbito interno do 
museu, que incluí atualizações constantes e monitoramento das demandas e comportamentos de indivíduos e grupos sociais.

\section{Perfil do brasileiro no uso da Internet e nas novas tecnologias de comunicação.}

Neste cenário, não deveria ser surpresa verificar que algumas comunidades online têm silenciosamente transformado a sociedade, na realidade, como uma força capaz de unir milhões de seguidores que apoiam e replicam ideias de 'líderes’ que se posicionam politicamente, e cujas plataformas em redes sociais ecoam através de mensagens escritas, mas também de áudios e vídeos, surpreendendo os que não se mobilizam ou que utilizam forma tão direta de comunicação. Esta mobilidade descentralizada se mostrou capaz, como de fato, contribuiu para a tomada do poder político no Brasil de 2018, onde o 'direito’ (ou dever) de votar é obrigatório. Este fato, a rigor, pode passar desapercebido, mas indica a força que a comunicação e mobilização através das redes sociais podem representar numa sociedade como a brasileira, senão vejamos: o país possui 147 milhões de eleitores ${ }^{1}$ e é formado por vinte e seis Estados Federados (e o Distrito Federal) com cerca de 210 milhões de habitantes. Ele ocupa a $5^{\mathrm{a}}$ maior superfície terrestre do globo marcada por fronteiras políticas, e tem como idioma unificador, o português. Uma característica interessante é a diversidade de seus habitantes, composta por extratos sociais de diferentes origens e com altas taxas de miscigenação entre si. Com cinco mil quilómetros da ponta Sul até o extremo Norte, e de Leste a Oeste, no eixo nordestenoroeste, sua área mais larga ainda é selvagem ou carece de infraestrutura, e a densidade populacional é inexpressiva e culturalmente tímida. De clima seco e quase desértico no interior do Nordeste, quente e úmido no Norte e noroeste, o país tem reduzido território em clima temperado que, geograficamente, aponta para o Sul. O sudeste e a região Sul do Brasil, onde a marca migratória europeia é mais forte, a indústria e o nível de escolaridade se destacam. A escassa densidade populacional é uma característica do centro-oeste brasileiro, onde há a transição entre dois ecossistemas; o amazônico e o pantanal que ainda domina a região, mas que perde cada vez mais espaço para as monoculturas como as da soja e do algodão.

No Brasil, de uma forma geral, as desigualdades regionais são notáveis e chamam atenção, tanto em termos de população quanto em nível de educação formal, de urbanismo e de estruturas. Os recursos naturais, o mercado interno, a agropecuária e a indústria têm potência global, porém, problemas persistentes, que talvez tenham relação com o 
processo histórico de viabilidade econômica da nação, imprimem uma mancha social colorida pela violência, pela corrupção, crise de valores e falta estabilidade política. Tais máculas refletem no fraco crescimento econômico, no alto índice de desemprego e baixos níveis culturais da população, além das desigualdades acentuadas ${ }^{2}$, que não seriam merecidas só pelos atributos positivos citados. É interessante destacar que o território brasileiro está inserido em uma espécie de 'ponta de lança' do mundo ocidental, como outros países do continente americano, os últimos territórios a serem colonizados por europeus nos moldes tradicionais do início da idade moderna, quando eles trouxeram seus arcabouços mercantis e religiosos da época. Verifica-se, contudo, que no século XXI, o país apresenta especificidades únicas. As características citadas até então, que são geográficas, culturais ou sociais, aparecem no comportamento da população brasileira em termos do uso de tecnologia de comunicação, o que interessa muito aos museus e seus administradores. A participação nas redes sociais através da Internet, o uso e o interesse por novas tecnologias como aparelhos e aplicativos de telefones móveis são importantes no Brasil.

De acordo com o relatório do Instituto McKinsey Brazil Digital Report, $2019^{3}$ (p.35), são 83 milhões de pessoas que usam a Internet diariamente, (dois a cada três brasileiros) fato que coloca o país acima da média entre outros que mais usam dispositivos de acesso à Internet. Além disso, em termos de horas por dia (online), o índice é um dos mais altos. Segundo o Google ${ }^{4}$, os brasileiros, em 2018, passaram, em média, 9 horas por dia conectados, quase metade via aparelho celular, e cerca de 3,5 horas diárias postando nas mídias sociais, um acréscimo de $12 \%$ em relação aos últimos 4 anos. É importante pontuar que $95 \%$ da população possui smartphones. Ainda segundo a mesma fonte, no Brasil, são 20 milhões de usuários do aplicativo e serviços de Uber, 7 milhões de assinantes da Netflix ${ }^{5}$. O estudo do Instituto McKinsey posiciona o país em $2^{\circ}$ ou $3^{\circ}$ lugares entre os que mais interagem nas plataformas de mídia sociais, incluindo Facebook, (130 milhões de usuários, terceira maior base de usuários do mundo e piloto para novos produtos como stories para eventos, conteúdo de jogos etc.). O Instagram (mais de 50 milhões de usuários, segunda maior base de usuários), YouTube, (o segundo no mundo com cerca de 69 milhões de visualizações por mês), WhatsApp, (mais de 120 milhões de usuários, o aplicativo de comunicação mais utilizado no Brasil, com penetração de 91\% entre usuários da Internet.), e Linkedln, com 29 milhões de usuários, a $3^{\text {a }}$ maior base mundial. A pesquisa aponta que $95 \%$ da população possui aparelho de 
televisão, 89\% tem telefone celular de qualquer tipo, (71\% smartphone), 38\%, possui laptop ou desktop e 15\% tem tablets. A metodologia da investigação realizada em novembro de $2018^{6}$, sobre participação dos brasileiros nas redes sociais, utilizou amostragem estratificada de 2.477 pessoas residentes em áreas urbanas, entre 15 e 60

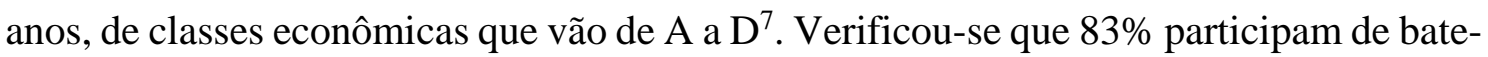
papo online, 56\% de redes sociais, 54\% assistem notícias e utilizam ferramentas de busca, além de grande utilização de e-mails diários (41 milhões).

Verifica-se que há muito espaço para inclusão digital entre a população ${ }^{8}$, e o potencial de crescimento dos ramos digitais e tecnológicos se mostram como grandes oportunidades de negócios, especialmente no e-commerce e no ensino a distância (EaD), que vem crescendo e se consolidando ${ }^{9}$, apesar dos problemas de qualidade de alguns cursos ou da falta de recursos tecnológicos em outros, além da fraca qualificação de alguns 'monitores'. A utilização de livros online aparece em apenas $2 \%$ da população pesquisada. Além disso, oportuno pontuar que os domicílios com renda mais alta tem quase 4 vezes mais penetração na Internet do que os de moradias de renda mais baixa, fato que isola e nega oportunidades a quem realmente necessita. Outra realidade que vale a pena mencionar é relativa à velocidade da Internet. Ainda que o país tenha subido cinco posições desde 2014, ficando em $133^{\circ}$ lugar entre os 200 países em 2018, com 2,58 mbps $^{10}$, ela ainda é a menor do que em muitas economias desenvolvidas ${ }^{11}$.

\section{Porto Alegre e seus Museus: um estudo de caso}

A cidade de Porto Alegre, capital do Estado do Rio Grande do Sul, estado mais ao Sul do Brasil, onde a marca imigratória internacional representa um importante patrimônio cultural, está inserida na $1^{\text {a }}$ Região Museal que, geograficamente, inclui os museus da capital e dos municípios próximos ao seu redor num raio de 100 quilômetros. Neste universerso localizamos cerca de 87 instituições ${ }^{12}$. Para melhor sistematizar nosso trabalho dividimos essas instituições por esfera de gestão, assim classificamos as instituições em Museus Federais, Estaduais, Municipais e particulares, conforme ilustramos nos gráficos que se seguem. 
Gráfico I

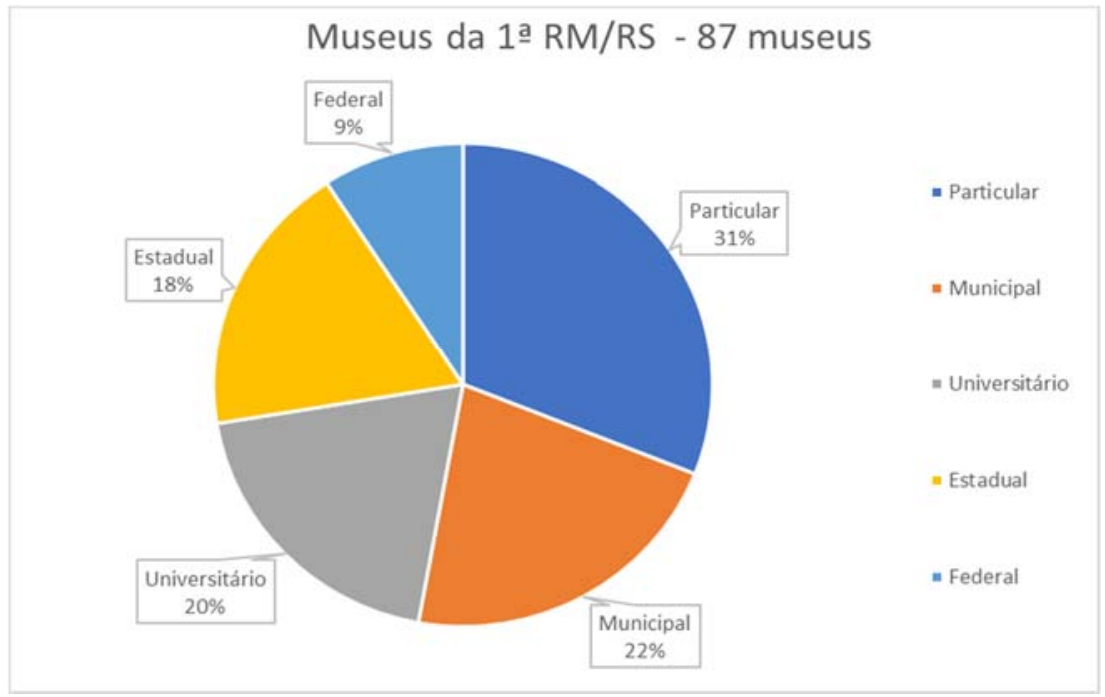

Entre os museus Federais estão os museus universitários e, entre os particulares, as Fundações. Também podemos separar os museus em temáticos, históricos, de ciências e de artes. Assim, o gráfico I, mostra que os museus estatais ou públicos somam $69 \%$ do total das instituições culturais, sendo o saldo representado pelos museus particulares que inclui as Fundações, Associações e demais Instituições privadas de uma maneira geral.

Gráfico II

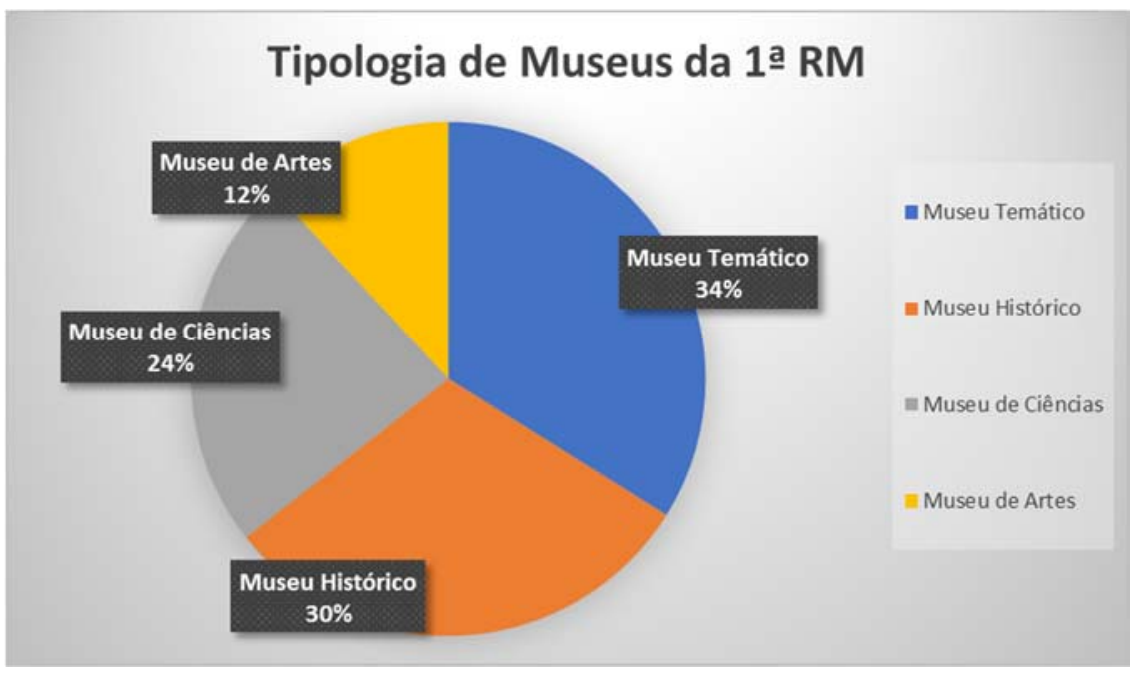

Entre os 87 museus (e centros culturais) pesquisados, que compõem a $1^{\text {a }}$ região museal $^{13}$, independentemente da sua gestão, convencionamos, para melhor compreensão, por aspectos de conteúdo, por exemplo: Museu do Carvão (Charqueadas), temático, Museu Histórico, como o Museu Júlio de Castilhos (capital), Museu de Artes; como a 
Fundação Iberê Camargo (capital) e de Ciências como do Museu de Ciências e Tecnologia (capital) da Universidade Católica do Rio Grande do Sul (PUCRS). Entre os museus presentes nas mídias sociais, ou seja, de acordo com nossa investigação dentro da citada região museal, se destaca a plataforma Facebook, como a de uso prioritário. O trabalho de pesquisa foi importante para conhecer a posição geral dos museus dentro da área de abrangência que trabalhamos, especialmente os que dispunham de representação na Internet ou aqueles não possuiam uma página própria ou ainda os que estavam fechados por ocasião de nossa pesquisa, conforme observamos no gráfico abaixo:

Gráfico III

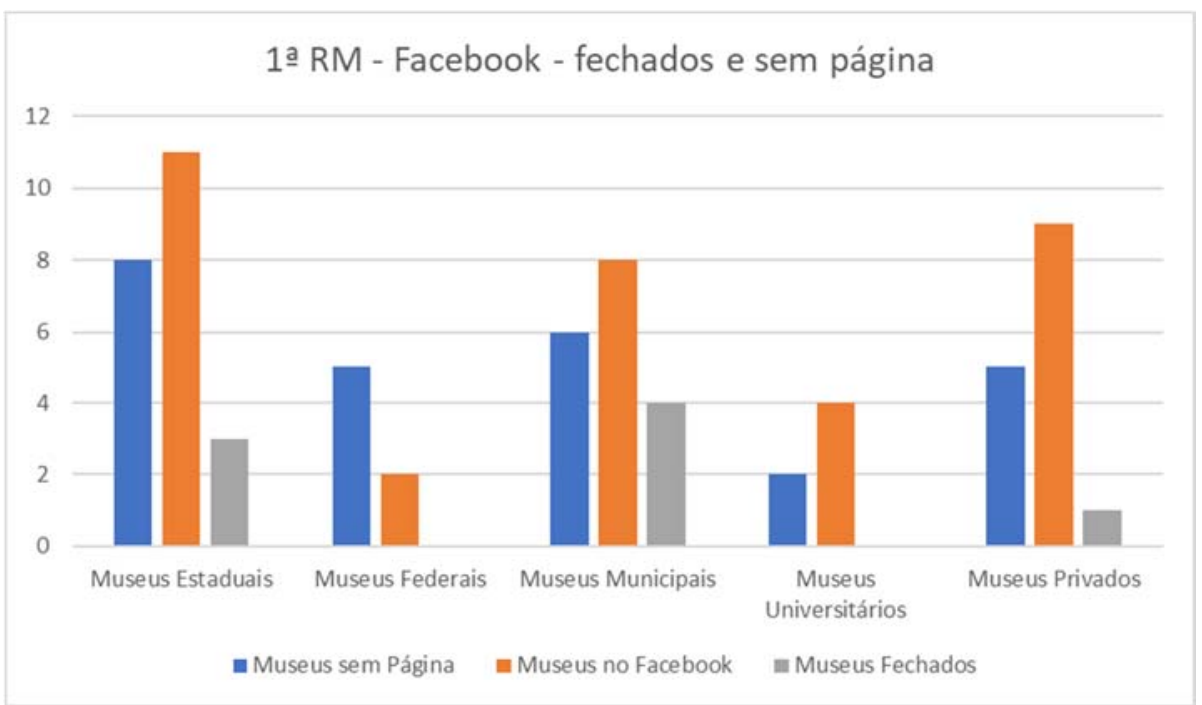

Gráfico IV

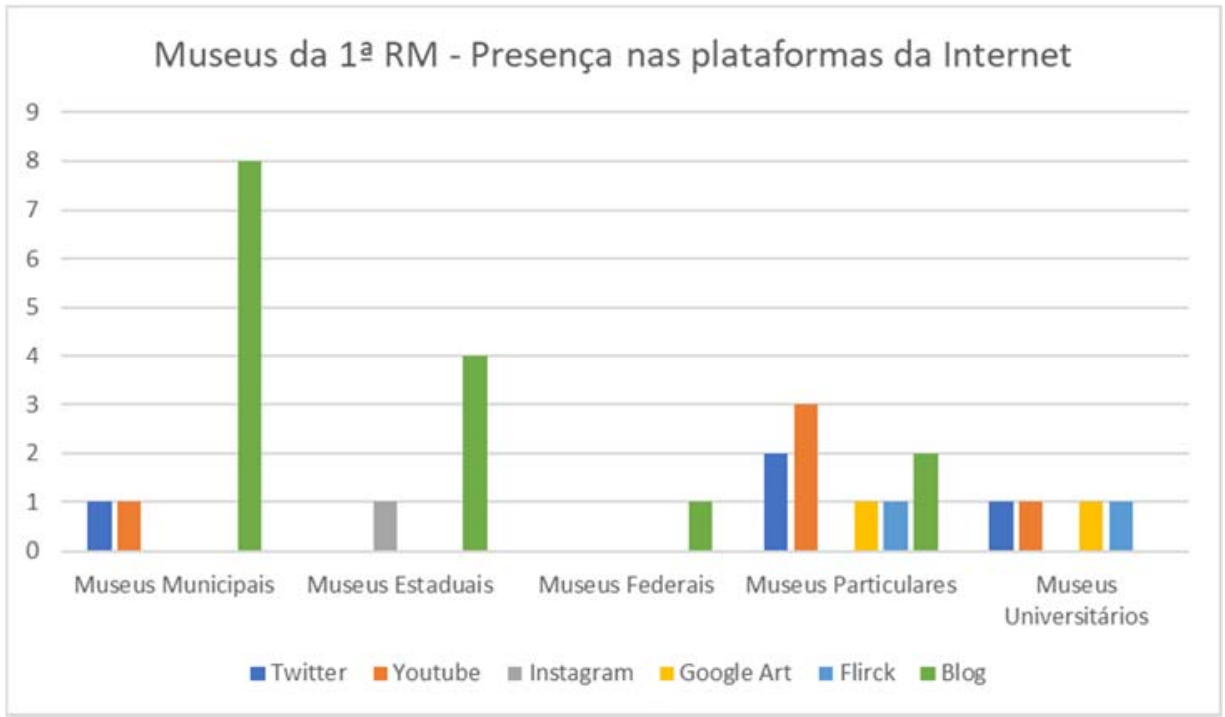


Quanto ao gráfico III, é fácil concluir, que alguns museus não podem sustentar página própria e alternativamente constroem uma página no Facebook, obviamente por questões de custos. Verificamos ainda que muitos museus estatais (Municípais ou Estaduais) utilizam-se da página de sua mantenedora (por exemplo: secretaria de cultura do município ou do estado, o qual está ligado) para obtenção de um espaço, dentro da plataforma pública de uma 'página própria’ na Internet. O gráfico IV representa uma visão mais ampla da participação dos museus da $1^{\mathrm{a}}$ região museal na Internet. (com excessão da plataforma Facebook). Destaca-se o uso de blogs pelos museus estatais (municipais em primeiro lugar), mas também a diversidade de mídias dos museus particulares e universitários. É importante pontuar que os blogs conferem uma importante participação popular nos assuntos do museus (ou intituição cultural), e também apontam para um interesse de participação que pode incluir fotos, filmes, podcast e textos. Isto talvez explique a maior proximidade do público com os museus municipais, que podem estar mais intimamente ligados aos seus conteúdos, mais cidadino e possivelmente mais conectados aos assuntos ou conteúdos que são mais valorizados pela comunidades locais.

\section{Os museus online, as tecnologias 'embarcadas' em museus e a crise de conceitos.}

Nesses últimos sete ou dez anos, assistimos um desdobramento exponencial de redes sociais que se disponibilizam ao público através da Internet, mas também o crescimento dos aplicativos tecnológicos para utilização através de dispositivos móveis. Em relação às novas tecnologias e os Museus, Rosali Henriques (2018), diz que existem três tipos de museus virtuais: o folheto eletrônico, o museu no mundo virtual e os museus realmente interativos. Segundo a autora, os folhetos eletrônicos são aqueles cujo objetivo é a apresentação do museu, funcionando como uma ferramenta de comunicação e marketing; já o museu no mundo virtual é aquele no qual a instituição apresenta informações mais detalhadas sobre seu acervo, com visitas virtuais. E, por último, os museus realmente interativos, que são aqueles onde existe uma relação entre o museu virtual e o museu físico, sendo acrescentados elementos de interatividade, que envolvem o visitante.

Quanto as mídias sociais, especialmente o Facebook, as autoras (López e Ciuffoli, 2012) questionam se a experiência da participação no aplicativo é realmente nova ou uma prática antiga que remontaria ao tempo de Gutemberg, no entanto, ainda segundo suas análises “quando tocadas pela varinha mágica das tecnologias da instantaneidade e da 
massificação, apenas renovam antigos ritos e mitos”. Em resumo, o que o Facebook pode nos dizer sobre novas formas de ser e participar da Internet tem mais a ver com que ela faz conosco, mas também o que fazemos (e podemos fazer) com o Facebook. Entre acessões e quedas de plataformas (do Orkut para o Facebook), elas atraem cada vez mais a preferência e aderência de indivíduos e grupos sociais ${ }^{14}$. $\mathrm{O}$ fenômeno se combina com a capacidade e vontade das pessoas que, participando, aparecem socialmente e dizem aos outros um pouco como são. Não se deve contornar, porém, o grande e novo poder mercantil que está por de trás dessas mídias. Os processos de propaganda e monitoramento dessas individualidades (que são usuárias das redes sociais), usam ferramentas eletrônicas que ordenam os interesses, direcionando suas campanhas e processos de forma online, colhendo resultados em escala, mas também os compartilhando com grupos de interesses diversos.

. No âmbito das instituições culturais, as implicações em relação às formas de interação, tanto entre sujeitos quanto em relação aos objetos e os sujeitos, estão diretamente articuladas ao fato de como as pessoas passam a agir nos contextos sociais, condicionados pelos imperativos tecnológicos provenientes das experiências pregressas. De acordo com Russ (at all, 2010), as redes sociais também representam mudanças nas formas como usuários interagem, utilizando diferentes modelos de comunicação: umpara-um (ex. de usuário para usuário) um-para-muitos (ex. museu para usuários, como em blogs) e muitos-para-muitos (ex. Wikis). Historicamente, os modelos de comunicação um-para-um e um-para-muitos proveram o framework para autoridades culturais como o estabelecido pelos programas de museus.

A engenharia em $\mathrm{TI}^{15}$ tem realizado grandes desenvolvimentos em termos de expografia e tecnologias dentro dos museus. Em relação a tecnologia incorporada junto aos acervos exibidos em exposições museológicas, digitalização de acervos salvaguardados em reserva técnica, entre outras novidades proporcionada por tecnologias disponíveis, e as que se desenvolvem com rapidez, sacodem-se as certezas e precipitam a revisão de conceitos como, por exemplo Patrimônio, Autoria de obras de arte e Sociedade Digital. Além disso, quando os bens materiais pertencentes a um museu são examinados, presume-se que cada objeto é único e requer atenção material individual a longo prazo, incluindo um ambiente de armazenamento adequado. Esta é uma das razões pelas quais tanta importância se dá à sustentabilidade das instituições. Do ponto de vista técnico, de acordo com Karp, (2004), é fácil duplicar um objeto digital original com total 
precisão. A dificuldade, nesse caso, é o risco de que a tecnologia utilizada para lhe reproduzir se torne obsoleta após a criação do registro digital, e que posteriormente seja impossível recuperar o objeto imaterial da mídia original de armazenamento. Nesse caso é necessário estar atento permanentemente e, a longo prazo, para que os objetos digitais sejam transferidos de um suporte para outro à medida que as tecnologias evoluam. A conservação do material dos suportes de armazenamento também é um problema, mas, como é parte de um domínio material mais familiar, muitas vezes somos levados a esquecer a dificuldade fundamental da preservação do material digital.

O modelo antigo de Museu ou Instituição histórica de memória (arquivo) e de informação (biblioteca), conforme destaca José Oliveira (2013, p.105), “quando o observador tem que ir ao museu, fazer um percurso exposição-sistema de documentaçãobiblioteca-arquivo, presencialmente em uma arquitetura que possui grandes deslocamentos, contato pessoal e imediato”. As possibilidades de reordenamento ou revisão de conceitos, historicamente nunca foi novidade. Segundo Cáceres, (2016, p.154) nos museus, elas representam a modernidade, e as informações contidas em seus sites, catálogos e junto ao acervo exposto representam uma seleção hierarquizadas, mas também uma forma de dominação que em nada difere do passado. Ainda assim, os museus se arrojam ao adotar tecnologias como por exemplo o QRCode ${ }^{16}$ que disponibilizam mais informações em etiquetas nos itens expostos, ou quando adotam novas tecnologias nas exibições que visam criar um tipo de organização reticular e de conhecimento, articulando o social e o cultural, aprimorando as informações e conteúdo. ${ }^{17}$ Ao aderir a rede de computadores, as possibilidades se ampliam uma vez que o hipertexto é mais rápido, encurta tempo e o espaço, mas sobretudo permite uma navegação que pode passar por imagens, áudios e diálogos online. É uma integração maior que o público conectado não abre mão. O museu, mas também o arquivo online e o hipertexto, no caso das bibliotecas, disponibilizariam todas as informações possíveis para o público e um universo de pesquisadores em tempo real. De acordo com Salima, 2007, (p.6) o uso inovador da Internet nessas instituições, especialmente nos museus, permite experimentar abordagens de tipo ‘empurrão’, isto é, destina-se a criar um canal de comunicação que está constantemente aberto aos seus usuários e visitantes. Um museu que começa a experimentar podcasting, que consiste em criar uma espécie de revista de mídia digital, para o qual um usuário pode participar e receber feedback contínuo, ou arquivos em diferentes formatos, que podem ser transferidos para o seu dispositivo portátil e usados 
de forma assíncrona, ou seja, em horários e locais definidos pelo usuário. Vários museus disponibilizam, guia de podcast, contendo a descrição sala por sala dos trabalhos apresentados em suas exposições.

O conceito de edutainment ${ }^{18}$ adquire assim um valor adicional: não é apenas entretenimento - geralmente associado a formas inovadoras de usar o conteúdo cultural, disponibilizado pela tecnologia - que pode apoiar o processo de aprendizagem de novos conhecimentos, mas sua proposição também é válida na forma inversa: a visita de fato, pode representar uma importante oportunidade para um museu adquirir maior familiaridade com os novos dispositivos digitais, ajudando a reduzir a resistência cognitiva daqueles que estão mais relutantes em se apropriar do novo potencial de transmissão de conhecimento oferecido pelo progresso científico. (Solima, 2007, p.8)

Portanto, não só eles estão mudando lugares de interação, sempre circunscrito pelos limites físicos do museu, mas também, e acima de tudo, modos de interação, cada vez mais aberta à ativação de trocas bidirecionais, capazes de responder às exigências das relações sociais emergentes. Alguns museus online, abrem espaços para comparação (quadro de discussão) sobre questões emergentes e tornam-las acessíveis ao público: os visitantes do site são convidados a expressar suas opiniões e compará-las com a de outros usuários. Os blogues ativados por museus e centros culturais são apenas um dos muitos exemplos de experimentação desta forma de troca de informações iniciada nos últimos anos. Por exemplo: nos dias de hoje, enquanto os artistas incorporam o aroma à experiência estética 'pairam' em torno de galerias expositivas dos museus o cheiro de pólvora, grama, jasmim, pinho, e patchouli. Outras redes sociais como Instagran, 500px, Flickr, Pinterest, Photobucket, PictureSocial e Bluecanvas são especialistas em arte e fotografia, que podem ser postadas pelos autores e compartilhadas com o público ou ainda sites que os próprios artistas participam para divulgar seus trabalhos. ${ }^{19}$

\section{Conclusão}

A perspectiva tecnológica estará ao lado do museu apoiando o seu desenvolvimento, caso contrário ele arriscará sua capacidade de se apresentar como um interlocutor capaz não apenas de estimular perguntas, mas de fornecer respostas adequadas às muitas questões que, fatalmente a visita a essas galerias contribui para despertar. Conectar para inovar e como utilizar as potencialidades digitais para gerar recursos para museus e instituições culturais? Como aplicar práticas de mobilização de 
recursos para serem utilizados por organizações sociais? Quais práticas inovadoras que unem a consciência de economias compartilhadas e canais digitais, que podem apoiar a sustentabilidade financeira de museus e centros culturais? Essas são perguntas para refletir junto a perspectiva do uso de tecnologia nos museus e instituições culturais.

O uso de algumas das soluções tecnológicas descritas neste artigo implica, de fato, uma certa familiaridade do usuário em relação ao ambiente digital, bem como uma propensão ao uso de tais ferramentas, que não podem ser referidas à questões consideradas em sua totalidade, devido à presença de diferenças significativas relacionadas ao gênero, ou à idade ou status profissional. No Brasil, conforme foi dito há um número potencial de usuários que ainda restam aderir às novas demandas que são voltadas para a experimentação de tecnologias e a socialização de seus conhecimentos.

A questão que se formula é: qual o museu que queremos? Ele certamente sempre será presencial e de qualidade, contudo, não podemos nos impor sobre a modernidade e as mudanças tecnológicas que chegam com toda força. Assim, devemos questionar se os museus estão empenhados em participar integralmente neste domínio, assumindo a aplicação das novas tecnologias como exercício prioritário, no sentido em que elas também podem sustentar as restantes funções museológicas. A Internet implica potencialidades na revitalização da comunicação política, mas esse potencial é vulnerável de acordo com a infraestrutura social e econômica que a rodeia. Na região da cidade de Porto Alegre, como em um espelho que se aplica a outras cidades do mundo, foi possível averiguar que as mídias sociais e a tecnologia estão presentes, democratizando a informação, e que elas auxiliam no trabalho do museu em realizar sua missão. Estas novas ferramentas nos mostram que a necessidade de memória e cultura são exigências da população, pois estão representadas em todos os níveis da administração pública, mas também atraem o interesse de grupos privados, e conforme verificamos em alguns casos, são capazes de se manter sustentáveis sem ligação com o aparato estatal. 


\section{NOTAS}

1 As eleições gerais no Brasil se dão a cada 4 anos, e apesar do alto número de pessoas que participam em um só dia (entre as 9:00 e 18h) é apurado, geralmente, em 24h, devido a utilização de dispositivos eletrônicos, como urna eletrônica e biometria. Fonte: http://www.tse.jus.br/imprensa/noticiastse/2018/Agosto/brasil-tem-147-3-milhoes-de-eleitores-aptos-a-votar-nas-eleicoes-2018. Acesso em 12.06.19.

${ }^{2}$ Fonte: https://portal.fgv.br/noticias/pobreza-e-desigualdade-aumentaram-ultimos-4-anos-brasil-revelaestudo Acesso em 09.06.19.

${ }^{3}$ Fonte: https://www.brazilatsiliconvalley.com/brazil-digital-report, captado na Internet em 9.06.19, apresenta uma visão geral da economia brasileira, mas também da inovação incluindo o cenário digital. Os dados mostram que o país oferece oportunidades surpreendentes e números impressionantes, mas também muitos desafios em termos de inovação e produtividade, seus piores desempenhos. visando impulsionar crescimento e avanço social.

${ }^{4}$ CETIC.br; Consumer Barometer Google (2018). Disponível: https://www.consumerbarometer.com/en/ acessado em 10.06.19.

${ }^{5} \mathrm{O}$ maior entre os não anglo-fônicos.

${ }^{6}$ Ibidem nota 3.

${ }^{7}$ A grande diferença econômica e social existente no país estratifica sua polução em diversos níveis sócio econômicos, sendo 'A' correspondente a classe economicamente privilegiada e 'D', a dos cidadãos menos privilegiados ou pobres.

${ }^{8}$ Ibidem nota 3.

${ }^{9}$ O Ensino a Distância (EaD) cresceu 17,6\% de 2016 para 2017, chegando a quase 1,8 milhão de alunos em 2017 o equivalente a $21,2 \%$ do total de matrículas em todo o ensino superior. O número de cursos no país também aumentou, de 2016 para 2017, passou de 1.662 para 2.108, o que representa aumento de 26,8\% maior crescimento desde 2009, quando o país passou dos 647 cursos registrados até 2008 para 844 cursos. Fonte: Ibidem nota 3.

${ }^{10}$ Fonte: https://forbes.uol.com.br/listas/2018/09/10-paises-com-internet-mais-rapida-do-mundo/. Acesso em 08.06.2019.

${ }^{11}$ Ibidem nota 3.

12 Não foi possível inserir neste artigo a lista completa dos 87 museus, seus nomes e localizações, por uma questão de tempo, no entanto, o leitor que nos solicitar podemos enviar por correio eletrônico.

13 A pesquisa foi realizada em maio de 2018, e (em agosto de 2019) encontra-se em revisão.

${ }^{14}$ Soma-se a isso a acessibilidade dos dispositivos como computadores, tablets e aparelhos celulares modernos com inúmeros recursos, que se tornam, através dos mecanismos de crédito ao grande público, cada vez mais fácil e barato de adquirir, realidade impulsionada pela produção da indústria da informática. 15 TI (Tecnologia da Informação) ou Engenharia de software é uma área da voltada à especificação, desenvolvimento, manutenção e criação de programas de computador, com a aplicação de tecnologias e práticas de gerência de projetos entre outras disciplinas. Visa a educação, a produtividade e a qualidade.

${ }^{16}$ É um código de barras em 2D que pode ser escaneado pelos aparelhos celulares. Esse código, após a decodificação, passa a ser um trecho de texto, um link que irá redirecionar o acesso ao conteúdo publicado em algum site. Fonte:https://www.triscele.com.br/triscele/interatividade/qr-code-em-exposicoesmuseologicas Acesso em 02.06.19.

${ }^{17}$ Aqui um exemplo: https://www.handbuiltcreative.com.au/\#work Acesso em 06.06.19.

${ }^{18}$ Edutainment, a união entre educação e entretenimento. Ou edtech, sigla, em inglês, que se refere à junção de educação e tecnologia.(Fonte: https://envolverde.cartacapital.com.br/edutainment-a-uniao-entreeducacao-e-entretenimento/ Acesso em 07.06.19.

19 Fonte: http://www.tecnoartenews.com/noticias/15-redes-sociais-para-artistas-compartilharem-seustrabalhos/ Acesso em 02.06.19. 


\section{Referências:}

CACÉRES, Jesús Galindo Ingeniaria em Comunicacion Social y los Museus: Apunte hacia um programa de investigacion-acción. IN: MORIGI, Waldir at all (Org) Epistemologias Comunicação e Informação. Editora Meridional, Porto Alegre, 2016. 233p.

DODEBEI, Vera Doyle Patrimônio e Memória Digital Baseado e texto de discussão na Mesa Redonda "Patrimônio digital: os desafios do cientista social” realizada no XXIX 2012Encontro Anual da ANPOCS, 25 a 29 de outubro de 2005, Caxambu, MG.

GRAU, Oliver Arte Visual: da ilusão à imersão São Paulo: Editora UNESP: Editora Senac, Sã Paulo, 2007.

HENRIQUES, Rosali Os museus virtuais: conceitos e configurações Cadernos de Sociomuseologia (vol. 56) $\mathrm{n}^{\circ} 12-2018$.

KARP, Cary El patrimonio digital de los museos en línea. Museum Internacional, UNESCO, 2004. (p, 44-51.)

LOPÉZ, Guadalupe; Ciuffoli, Clara. Facebook es el mensaje: oralidad, escritura y después, Crujía ediciones, Buenos Aires, 2012.

OLIVEIRA, José Cláudio Alves de Os acervos dos museus no ciberespaço: compartilhamento e (des) informação Cadernos de Socio-museologia - 2-2013. (vol. 46)

RUSS, A. WATKINS, J, KELLY, L \& CHAN, S. Como as mídias sociais afetam a comunicação nos museus. Lumina Revista do Programa de Pós-Graduação em Comunicação da Universidade Federal de Juiz de Fora, V.4 n.1, 2010.

SANTOS, Maria Célia. Encontros Museológicos - Reflexões sobre a Museologia, a Educação e o Museu. (Coleção Museu, Memória e Cidadania, 4), Rio de Janeiro, 2008.

SOLIMA, Ludovico Nuove tecnologie della comunicazione Economia dela Cultura - a. Xvii, 2007, n. 3.

SCHREIBMAN, S., SIEMENS, R., \& UNSWORTH, J. (Eds.) The digital humanities and humanities computing: an introduction., A Companion to Digital Humanities. Malden, Oxford: MA, Blackwel. 2004. Retrieved from http://www.digitalhumanities.org/companion/view?docId=blackwell/9781405103213/9 781405103213.xml\&chunk.id=ss1-1-3\&toc.depth=1\&toc.id=ss1-1-3\&brand=default

TOKARNIA, Mariana Educação a distância cresce 17,6\% em 2017; maior salto desde 2008. AGÊNCIA BRASIL. Publicado em 20/09/2018 - 11:03 Brasília, 2018. 